\title{
Suitability Assessment of Sabon Kaura Pit Gravel as Coarse Aggregate in Concrete Production
}

\author{
Agboola Shamsudeen Abdulazeez ${ }^{1}$, Mamman Adamu Idi ${ }^{2}$, Amina Omolola Suleiman ${ }^{3}$, Simdima Gabriel Gideon ${ }^{4}$ \\ ${ }^{1 \& 3,}$ M.Tech Student, Abubakar Tafawa Balewa University Bauchi, Nigeria \\ ${ }^{2}$ Abubakar Tafawa Balewa University Bauchi, Nigeria \\ ${ }^{4}$ Maintenance Department Federal Character Commission Abuja, Nigeria
}

\begin{abstract}
There is global need for the preservation of natural resources. Natural resources in the world are continuously decreasing due to manufacturing of the products and this has negative impact on the environment. Aggregates constitute large ratio by weight concrete production. Recently the approach is to research for alternative that will serve the purpose of the natural aggregates in concrete for sustainable construction. One approach to contribute to sustainable construction is to partially or totally replace natural aggregates. Pit gravel is a suitable material for replacement of aggregate in concrete production. Specific gravity as well as bulk density, porosity, Impact value, crushing value for both conventional aggregate and pit gravel were carried out. Workability, compressive strength and flexural strength properties of concrete produced with $100 \%$ conventional aggregate and pit gravel were carried out with a mix ratio 1:2:3 and water-cement ratio of 0.5 were examined and compared. The concrete was tested at 3, 7, 14 and 28 days' hydration periods. The results showed that concrete with both conventional and pit gravel has a medium workability. The highest compressive strength at 28 days was $27.53 \mathrm{~N} / \mathrm{mm}^{2}$ for conventional aggregate concrete as compared to $26.61 \mathrm{~N} / \mathrm{mm}^{2}$ for pit gravel concrete. The highest flexural strength at 28 days was $5.73 \mathrm{~N} / \mathrm{mm}^{2}$ for conventional aggregate concrete as compared to $5.67 \mathrm{~N} / \mathrm{mm}^{2}$ for pit gravel concrete. The strength test results indicated that conventional aggregate concrete gave better strength compared to pit gravel concrete. The research recommends use of pit gravel to fully replace conventional aggregate in concrete.
\end{abstract}

Keywords - Conventional Aggregate, Pit Gravel, specific gravity, Bulk density, Porosity, Aggregate impact value, Aggregate crushing value, Workability, Compressive strength, Flexural strength.

\section{INTRODUCTION}

$\mathrm{C}$ oncrete is a widely used construction material around the world. It is due to its wide ranging applications, performance properties, suitability and the ease of production. It is the second most consumed substance on Earth after water [1]. The concrete industry, due to its sheer size, has a considerable impact on the environment. In the same vein natural resources in the world are continuously decreasing due to manufacturing of the products and this has negative impact on the environment. According to [2], the usage of concrete is around 10 billion tons per year, which is equivalent to 1 ton per every living person. This high production and consumption of concrete is due to the continuous increase in the global population.

The rapidly growing public concern and rapid growth in the use of concrete materials is a phenomenon that we can no longer continue to ignore due to the unrestricted depletion of natural resources. On the other hand, we cannot neglect the issue of economic pressure, with effect of high cost of construction materials. Conventional concrete is composed mainly of cement, coarse aggregate, fine aggregate and water. However, around $75 \%$ to $90 \%$ of the volume of concrete consists of raw materials extracted from the ground. From the above it can be seen that concrete is thus a conspicuous consumer of large primary resources and this is a major concern in the drive to achieve sustainability within construction. In essence, it is of paramount importance to look into incorporating low cost material in the production of concrete to mitigate the overburden and over dependence on conventional material used in the production of concrete. The problem of over dependence on conventional materials for concrete production can be solved by diverting our attention towards sourcing of local alternative materials not only for concrete production purposes but also for building and construction in general. One of the suggestions in the forefront has been the sourcing, development and use of alternative, non-conventional local construction materials in construction works [3].

The construction industry is uniquely positioned to meet the challenges of sustainable development by reducing the quantity of cement in concrete and by using alternate building materials. Cement can be replaced by alternative natural or artificial cementitious material. Similarly, conventional aggregates can be replaced by alternative natural or artificial aggregates. One approach to contribute sustainable construction is to partially or totally replace natural aggregates. Aggregates constitute about $70 \%$ by weight of the concrete. There is a great demand for natural aggregates as the construction activities are increasing every day. As the natural resources are decreasing every day, some alternative materials that will serve the purpose of the natural aggregates should be introduced [4]. Researches looks into cheap materials that would serve perfect substitutes for such material while still meeting the set requirements for concrete 
in the industry [5]. However, this research looks into alternative aggregate material as substitute for conventional aggregate in concrete.

Due to depletion of natural granite stone, pit gravel can be used as an alternative material for coarse aggregate. Pit gravel is sourced from the river bed as a result of alluvial action. It is deposited in different sizes and grading. The suitability of pit gravel for a particular end-use is dependent on their physical properties such as texture, toughness, grainsize, grain-shape, density. Pit gravel is excessively cellular, glassy and has the same basic composition of quartzite. Pit gravel is round or sometimes irregular in form and generally has the basic composition of quartzite. Pit gravel is usually heavier, lighter and dirty white in nature. [6] observed that, many developed countries, are using natural materials and man-made materials as substitutes for natural stone aggregates. This material is vital in modern construction to reduce overburden on conventional materials.

The properties of concrete produced with conventional aggregate are known which are mostly of standard while properties of concrete produced with Sabon Kaura pit gravel are yet to be assessed. The availability and affordability of Sabon Kaura pit gravel had necessitated this research. Therefore, this research is to assess the suitability of Pit gravel from Sabon Kaura as substitute for coarse aggregate in concrete production, in order to determine the properties of conventional aggregate with non-conventional aggregate of pit gravel in Sabon Kaura Bauchi Local Government area Bauchi State.

\section{MATERIALS AND METHODS}

All the materials used for laboratory experiment were procured from the immediate environment. The relevant standards were used in the process of conducting the experiments.

\section{* Materials}

The materials used for this study include, coarse aggregate, fine aggregate, pit gravel, cement and water. Pit gravel was gotten from Sabon Kaura river bed in Bauchi state, Nigeria, and crushed with hammer to determine the size of the coarse aggregate needed for this work. The coarse aggregate was obtained from a quarry site within Bauchi metropolis. The fine aggregate was obtained from Yelwa River-flow in Bauchi state. The ordinary Portland cement is the brand of Dangote of Grade 42.5 which was procured from vendors within Bauchi metropolis.

\section{* Specific Gravity}

In determining the specific gravity of aggregate a pycnometer (a vessel of 1-liter capacity with a metal conical screw top and a $5 \mathrm{~mm}$ diameter hole at it apex, giving a water tight connection), tray, scoop, drying cloth and weighing balance were used. The test procedure was carried out in accordance to [7]. The apparatus used during the test include density bottle and stopper, funnel, spatula and weighing balance.

\section{* Bulk Density}

In determining the bulk density for pit gravel and conventional coarse aggregate a weighing balance, metal cylinder of $7 \mathrm{dm}^{3}$ capacity, scoop, straight edge, tamping rod of $16 \mathrm{~mm}$ diameter and a drying duster (towel) were used. The test was carried out according to [7].

\section{* Void Ratio of Aggregate}

Void Ratio was conducted in accordance with [7]. Void ratio has great effect on durability of concrete. The following equation is used for calculating void ratio of aggregate.

$$
\begin{gathered}
\text { Void Ratio }=\frac{\text { Uncompacted bulk density }}{\text { S.G x W }} \\
\text { Aggregate Porosity }
\end{gathered}
$$

Porosity is the ratio of volume of pores of a material to the total volume. It is the measure of how porous a material is. The pore spacing in aggregate determines the rate at which water can penetrate the aggregate. The percentage porosity of the aggregate should fall within the limit range specified by [8].

$$
\begin{aligned}
& \text { Percentage Porosity }=1-\frac{\text { Uncompacted bulk density }}{\text { Compacted bulk density }} \times 100 \\
& * \quad \text { Aggregate Impact Value }
\end{aligned}
$$

Aggregate impact value is the resistance of aggregate to failure through impact load. Aggregate impact value is the measure of resistance of aggregate to sudden shock. It is the ability of aggregate to resist sudden impact load on it. The tests were conducted in accordance with [9].

\section{Aggregate Impact Value}

$$
\begin{gathered}
=\frac{\text { Weight Passing through } 2.36 \mathrm{~mm} \text { sieve }}{\text { Weight of dry Aggregate }} \times 100 \\
\star \quad \text { Aggregate Crushing Value }
\end{gathered}
$$

Aggregate Crushing value is the ratio of a weight of fines passing through a specified sieve to the weight of the sample expressed as a percentage. Crushing value is the relative resistance of aggregate to crushing under gradual compressive load. The strength of coarse aggregate is determined by aggregate crushing test. The tests were conducted in accordance with [9].

\section{* Mix Ratio}

A 1: 2: 3 mix ratio was designed using a water cement ratio of 0.5 . Pit gravel is used to substitute $100 \%$ conventional coarse aggregate.

* Workability Tests of the Wet Concrete

Slump test and compacting factor test were conducted in accordance with [10]. 


\section{* Curing}

The specimens were removed from mould after 24 hours and taken to the water curing tank for the required curing days. The curing period include 3 days, 7 days, 14 days and 28 days. After the required curing period, tests were conducted on the hardened concrete. Curing process is used in enhancing and promoting the hydration of cement in concrete and also improve performance of concrete specimen.

\section{* Density Test}

This was carried out prior to crushing of the concrete specimen. At the end of each curing period, the concrete specimens were weighed using an electric weighing machine balance and recorded. Density is calculated as mass of concrete specimen in $(\mathrm{kg})$ divided by volume of concrete cube $\left(\mathrm{m}^{3}\right)$ and expressed in $\mathrm{kg} / \mathrm{m}^{3}$.

$$
\begin{aligned}
\text { Density } & =\frac{\mathrm{m}}{\mathrm{v}} \\
* & \text { Compressive Strength Test of Concrete }
\end{aligned}
$$

The compressive strength test was conducted in accordance with [11]. The cubes were cast and cured for 3days, 7 days, 14 days and 28 days respectively. For each mix, 3 cubes were crushed to obtain the average strength of the concrete samples. The compressive strength is the ratio of the weight of cube and the cross sectional area.

\section{* Flexural Strength Test of concrete}

The flexural strength test was conducted in accordance with [11]. The beams were cast and cured for 28 days only. For each mix, 3 beams were placed and subjected to breaking machine to obtain the average strength of the concrete samples.

\section{RESULTS AND DISCUSSION}

\section{* Specific Gravity}

The specific gravity of aggregate is presented in Table 1, 2 and 3 . The result shows that specific gravity of conventional coarse aggregate is 2.73; for pit gravel is 2.63, while the specific gravity of fine aggregate is 2.65. According to [9], the specific gravity for aggregate should fall within 2.60 to 2.80. However, the specific gravity of the aggregates falls within the limit as specified by the standard.

\section{* Bulk Density}

The bulk density for aggregates is presented in Table 4, 5 and 6. The result shows that compacted and un-compacted bulk density of conventional coarse aggregate is $1699 \mathrm{~kg} / \mathrm{m}^{3}$ and $1458 \mathrm{~kg} / \mathrm{m}^{3}$ respectively that of pit gravel for compacted and un-compacted bulk density is $1667 \mathrm{~kg} / \mathrm{m}^{3}$ and $1329 \mathrm{~kg} / \mathrm{m}^{3}$ respectively, while the compacted and un-compacted bulk density of fine aggregate is $1615 \mathrm{~kg} / \mathrm{m}^{3}$ and $1518 \mathrm{~kg} / \mathrm{m}^{3}$ respectively. The bulk density for a coarse aggregate range between $1200 \mathrm{~kg} / \mathrm{m}^{3}-1800 \mathrm{~kg} / \mathrm{m}^{3}$. The average value of the aggregates bulk density calculated all fall within the limit specified by [9].

\section{* Void Ratio}

The void ratio is presented in Table 7 . The result shows that void ratio of conventional coarse aggregate is 0.47 ; for pit gravel is 0.49 , while the specific gravity of fine aggregate is 0.43 . The result of the void ratio falls within the limit as specified by the [9].

\section{* Percentage Porosity}

The void ratio is presented in Table 8 . The result shows that Percentage porosity of conventional coarse aggregate is $14 \%$; for pit gravel is $20 \%$, while the percentage porosity of fine aggregate is $6 \%$. The average values obtained from the research shows that the aggregate falls within the limit of percentage porosity as specified by the [8].

\section{* Aggregate Impact Value (AIV)}

The aggregate impact value is presented in Table 9 and 10. The result shows that the AIV for conventional aggregate is $17.67 \%$, while the AIV for pit gravel is $19.55 \%$. This fall within the range of strong aggregate, as specified by [8] which state that value below $10 \%$ is an exceptionally strong aggregate, $10-20 \%$ is classified as strong aggregate, $20-30 \%$ as satisfactory, while value above $30 \%$ is termed as weak. However, both the conventional aggregate and pit gravel is classified as strong.

\section{* Aggregate Crushing Value (ACV)}

The aggregate crushing value is presented in Table 11 and 12. The result shows that the ACV for conventional aggregate is $28.78 \%$, while the ACV for pit gravel is $29.12 \%$. This fall within the range as specified by [8] which state that the maximum value for ACV should be $45 \%$ for normal weight aggregate to be used in pavements, road surfacing and other concrete works. However, conventional aggregate and pit gravel satisfied the requirement and can be used for concrete to be produced with normal weight aggregate.

\section{* Workability Test}

Table 13 shows the slump and compacting values for concrete containing conventional coarse aggregate and pit gravel. Test indicates that conventional aggregate concrete had slump value of $58 \mathrm{~mm}$, while pit gravel concrete has slump value of $52 \mathrm{~mm}$. Also for compacting factor test concrete containing conventional coarse aggregate has a compacting factor value of 0.93 , while the concrete produce with pit gravel has a compacting factor value of 0.90 . The test result indicated that the concrete is of medium degree workability. There was increase in the slump value of conventional aggregate concrete as compared to pit gravel concrete. The result also shows that pit gravel possesses the quality of conventional aggregate and can be used and applied in place of 
conventional aggregate in concrete production due its properties.

\section{* Density of Concrete}

Figure 1 present result on the density of concrete. Density values of concrete increase with increase in hydration period. Also the density of concrete cubes produced with conventional aggregate is higher as compared to concrete produced with pit gravel. In addition, from figure 2, an analysis can be drawn that the concrete beams produced conform to the density of normal-weight concrete, and favor higher durability due to the concrete value recorded higher than $2400 \mathrm{~kg} / \mathrm{m}^{3}$ for beam sample.

\section{* Compressive Strength of Concrete}

From Figure 2, compressive strength of concrete produced with conventional concrete which was maximum strength attained $13.71 \mathrm{~N} / \mathrm{mm}^{2}$ as compared to concrete produced with pit gravel which attained $13.13 \mathrm{~N} / \mathrm{mm}^{2}$ at 3 days' hydration period. For concrete made with normal-weight aggregate and used in foundations and slabs for low rise structures in nonaggressive soil conditions, a minimum strength class of $\mathrm{C} 8 / 10$ may be used provided the minimum cement content is not less than $180 \mathrm{~kg} / \mathrm{m}^{3}$ for designated concrete or $210 \mathrm{~kg} / \mathrm{m}^{3}$ for other types of concrete [11]. The results obtained at 3 days' hydration period and for all other hydration period, meet the $10 \mathrm{~N} / \mathrm{mm}^{2}$ provision of [11] for use as mass concrete, kerbs and floors. The cement content calculated stood at $400 \mathrm{~kg} / \mathrm{m}^{3}$, above the $180 \mathrm{~kg} / \mathrm{m}^{3}$ specified for designated concrete (General purpose nonstructural concrete).

At 7 days' hydration period concrete produced with conventional coarse aggregate attained $17.96 \mathrm{~N} / \mathrm{mm}^{2}$ as compared to concrete produced with pit gravel which attained $16.93 \mathrm{~N} / \mathrm{mm}^{2}$. The strength at 7 days' hydration period should attain $65-70 \%$ of expected compressive strength, $65 \%$ of $25 \mathrm{~N} / \mathrm{mm}^{2}$ is approximately $15 \mathrm{~N} / \mathrm{mm}^{2}$ as specified by [11]. At 14 days' hydration period concrete produced with conventional coarse aggregate attained $24.95 \mathrm{~N} / \mathrm{mm}^{2}$ as compared to concrete produced with pit gravel which attained $24.53 \mathrm{~N} / \mathrm{mm}^{2}$.

At 28 days' hydration period concrete produced with conventional coarse aggregate attained $27.53 \mathrm{~N} / \mathrm{mm}^{2}$ as compared to concrete produced with pit gravel which attained $26.61 \mathrm{~N} / \mathrm{mm}^{2}$. For reinforced concrete, the minimum strength class that should be used is LC16/18 for concrete made with lightweight aggregates, and C20/25 for concrete made with normal-weight aggregates [11]. According to [12], a document of the Hong Kong Government, stated that for reinforced concrete the lowest grade that should be used is C20 for concrete made with normal weight aggregate. To produce concrete with strength class C20/25 which is the minimum concrete strength class recommended for the construction of the load-bearing building structural members a minimum of 1:2:4 mix ratio and Portland-limestone cement grade 42.5 is required [13]. Therefore, concrete $\operatorname{mix}$ is expected to attain $25 \mathrm{~N} / \mathrm{mm}^{2}$ at hydration period of 28 days for general purpose structural works and $21 \mathrm{~N} / \mathrm{mm} 2$ for light reinforced concrete works.

\section{* Beam Test}

From the results of the flexural strength test shown in fig 4. The values of flexural strength as shown in the figure were $3.23 \mathrm{~N} / \mathrm{mm}^{2}, 4.37 \mathrm{~N} / \mathrm{mm}^{2}, 4.55 \mathrm{~N} / \mathrm{mm}^{2}$, and $6.13 \mathrm{~N} / \mathrm{mm}^{2}$ respectively for concrete produced with conventional aggregate, and $3.17 \mathrm{~N} / \mathrm{mm}^{2}, 4.37 \mathrm{~N} / \mathrm{mm}^{2}, 4.48 \mathrm{~N} / \mathrm{mm}^{2}$ and $5.97 \mathrm{~N} / \mathrm{mm}^{2}$ respectively for concrete produced with pit gravel at 28days curing period. It was observed that as compressive strength increases, it results in a corresponding increase in flexural strength. In essence as compressive strength increase with increase hydration period, flexural strength increase with increase in hydration period. This conforms to the relationship of Linear proportionality between flexural and compressive strength described by [14].

Table 1: Specific Gravity Test on Fine Aggregate

\begin{tabular}{lcll}
\hline Trial & Trial 1 & Trial 2 & Trial 3 \\
\hline Weight of empty cylinder $\left(\mathrm{M}_{1}\right) \mathrm{g}$ & 13.7 & 13.6 & 13.6 \\
Weight of cylinder + sample $\left(\mathrm{M}_{2}\right) \mathrm{g}$ & 95.2 & 69.3 & 67.1 \\
Weight of cylinder + water + sample $\left(\mathrm{M}_{3}\right) \mathrm{g}$ & 644.3 & 627.2 & 627.6 \\
Weight of cylinder + water $(\mathrm{M} 4) \mathrm{g}$ & 594.0 & 592.9 & 593.6 \\
Specific Gravity $=\frac{\mathrm{M} 2-\mathrm{M} 1}{(\mathrm{M} 4-\mathrm{M} 1)-(\mathrm{M} 3-\mathrm{M} 2)}$ & 2.61 & 2.60 & 2.74 \\
Average Specific Gravity & & 2.65 & \\
\hline
\end{tabular}

Table 2: Specific Gravity Test on Pit Gravel

\begin{tabular}{lccc}
\hline Trial & Trial 1 & Trial 2 & Trial 3 \\
\hline Weight of empty cylinder $\left(\mathrm{M}_{1}\right) \mathrm{g}$ & 117.6 & 117.6 & 117.6 \\
Weight of cylinder + sample $\left(\mathrm{M}_{2}\right) \mathrm{g}$ & 217.2 & 258.4 & 222.6 \\
Weight of cylinder + water + sample $\left(\mathrm{M}_{3}\right) \mathrm{g}$ & 499.2 & 524.1 & 500.6 \\
Weight of cylinder + water $(\mathrm{M} 4) \mathrm{g}$ & 436.8 & 436.3 & 436.8 \\
Specific Gravity $=\frac{\mathrm{M} 2-\mathrm{M} 1}{(\mathrm{M} 4-\mathrm{M} 1)-(\mathrm{M} 3-\mathrm{M} 2)}$ & 2.68 & 2.66 & 2.55 \\
Average Specific Gravity & & 2.63 & \\
\hline
\end{tabular}


International Journal of Latest Technology in Engineering, Management \& Applied Science (IJLTEMAS)

Volume X, Issue IX, September 2021|ISSN 2278-2540

Table 3: Specific Gravity Test on Coarse Aggregate

\begin{tabular}{|c|c|c|c|}
\hline Trial & Trial 1 & Trial 2 & Trial 3 \\
\hline Weight of empty cylinder $\left(\mathrm{M}_{1}\right) \mathrm{g}$ & 117.6 & 117.4 & 117.6 \\
\hline Weight of cylinder + sample $\left(\mathrm{M}_{2}\right) \mathrm{g}$ & 222.2 & 258.4 & 226.8 \\
\hline Weight of cylinder + water + sample $\left(\mathrm{M}_{3}\right) \mathrm{g}$ & 504.9 & 528.2 & 508.3 \\
\hline Weight of cylinder + water (M4) g & 438.9 & 438.9 & 438.9 \\
\hline Specific Gravity $=\frac{\mathrm{M} 2-\mathrm{M} 1}{(\mathrm{M} 4-\mathrm{M} 1)-(M 3-M 2)}$ & 2.71 & 2.73 & 2.74 \\
\hline Average Specific Gravity & & 2.73 & \\
\hline
\end{tabular}

Table 4: Bulk Density for Fine Aggregate

\begin{tabular}{lclllll}
\hline & \multicolumn{5}{c}{ COMPACTED } & UNCOMPACTED \\
\hline Trials & $\mathrm{C} 1$ & $\mathrm{C} 2$ & $\mathrm{C} 3$ & $\mathrm{C} 1$ & $\mathrm{C} 2$ & $\mathrm{C} 3$ \\
\hline Weight of empty cylinder $\left(\mathrm{M}_{1}\right) \mathrm{kg}$ & 8.10 & 8.10 & 8.10 & 8.10 & 8.10 & 8.10 \\
Volume of cylinder $\left(\mathrm{x} 10^{-3}\right) \mathrm{m}^{3}$ & 1.55 & 1.55 & 1.55 & 1.55 & 1.55 & 1.55 \\
Weight of cylinder + sample $\left(\mathrm{M}_{2}\right)$ & 10.64 & 10.57 & 10.60 & 10.52 & 10.41 & 10.43 \\
Weight of sample $\left(\mathrm{M}_{2}-\mathrm{M}_{1}\right) \mathrm{kg}$ & 2.54 & 2.47 & 2.50 & 2.42 & 2.31 & 2.33 \\
Bulk density $\rho=\frac{\mathrm{M} 2-\mathrm{M} 1}{\mathrm{volume}}$ & 1638 & 1594 & 1613 & 1561 & 1490 & 1503 \\
Average $=\frac{\mathrm{C} 1+\mathrm{C} 2+\mathrm{C} 3}{3}$ & $1615 \mathrm{~kg} / \mathrm{m}^{3}$ & & & $1518 \mathrm{~kg} / \mathrm{m}^{3}$ \\
\hline
\end{tabular}

Table 5: Bulk Density for Coarse Aggregate

\begin{tabular}{lclllll}
\hline & \multicolumn{7}{c}{ COMPACTED } & UNCOMPACTED \\
\hline Trials & $\mathrm{C} 1$ & $\mathrm{C} 2$ & $\mathrm{C} 3$ & $\mathrm{C} 1$ & $\mathrm{C} 2$ & $\mathrm{C} 3$ \\
\hline Weight of empty cylinder $\left(\mathrm{M}_{1}\right) \mathrm{kg}$ & 8.10 & 8.10 & 8.10 & 8.10 & 8.10 & 8.10 \\
Volume of cylinder $\left(\mathrm{x} 10^{-3}\right) \mathrm{m}^{3}$ & 1.55 & 1.55 & 1.55 & 1.55 & 1.55 & 1.55 \\
Weight of cylinder $+\mathrm{sample}\left(\mathrm{M}_{2}\right)$ & 10.74 & 10.76 & 10.70 & 10.38 & 10.24 & 10.46 \\
Weight of sample $\left(\mathrm{M}_{2}-\mathrm{M}_{1}\right) \mathrm{kg}$ & 2.64 & 2.66 & 2.60 & 2.28 & 2.14 & 2.36 \\
Bulk density $\rho=\frac{\mathrm{M} 2-\mathrm{M} 1}{\mathrm{volume}}$ & 1703 & 1716 & 1677 & 1471 & 1381 & 1523 \\
Average $=\frac{\mathrm{C} 1+\mathrm{C} 2+\mathrm{C} 3}{3}$ & $1699 \mathrm{~kg} / \mathrm{m}^{3}$ & & & & $1458 \mathrm{~kg} / \mathrm{m}^{3}$ & \\
\hline
\end{tabular}

Table 6: Bulk Density for Pit Gravel

\begin{tabular}{|c|c|c|c|c|c|c|}
\hline & \multicolumn{2}{|c|}{ COMPACTED } & \multicolumn{3}{|c|}{ UNCOMPACTED } & \multirow[b]{2}{*}{$\mathrm{C} 3$} \\
\hline Trials & $\mathrm{C} 1$ & $\mathrm{C} 2$ & $\mathrm{C} 3$ & $\mathrm{C} 1$ & $\mathrm{C} 2$ & \\
\hline Weight of empty cylinder $\left(\mathrm{M}_{1}\right) \mathrm{kg}$ & 8.10 & 8.10 & 8.10 & 8.10 & 8.10 & 8.10 \\
\hline Volume of cylinder $\left(\times 10^{-3}\right) \mathrm{m}^{3}$ & 1.55 & 1.55 & 1.55 & 1.55 & 1.55 & 1.55 \\
\hline Weight of cylinder + sample $\left(\mathrm{M}_{2}\right)$ & 10.61 & 10.75 & 10.69 & 10.08 & 10.14 & 10.26 \\
\hline Weight of sample $\left(M_{2}-M_{1}\right) \mathrm{kg}$ & 2.51 & 2.65 & 2.59 & 1.98 & 2.04 & 2.16 \\
\hline Bulk density $\rho=\frac{\mathrm{M} 2-\mathrm{M} 1}{\text { volume }}$ & 1619 & 1710 & 1671 & 1277 & 1316 & 1394 \\
\hline Average $=\frac{\mathrm{C} 1+\mathrm{C} 2+\mathrm{C} 3}{3}$ & \multicolumn{2}{|c|}{$1667 \mathrm{~kg} / \mathrm{m}^{3}$} & \multicolumn{3}{|c|}{$1329 \mathrm{~kg} / \mathrm{m}^{3}$} & \\
\hline
\end{tabular}

Table 7: Void Ratio of Aggregate

\begin{tabular}{llcll}
\hline Material & $\begin{array}{l}\text { Bulk Density } \\
(\rho) \mathrm{kg} / \mathrm{m}^{3}\end{array}$ & $\begin{array}{c}\text { Specific } \\
\text { Gravity }\end{array}$ & $\begin{array}{l}\text { Weight of } \\
\text { Water }(\mathrm{g})\end{array}$ & $\begin{array}{l}\text { Void Ratio } \\
(\mathrm{V} . \mathrm{R})\end{array}$ \\
\hline Fine aggregate & 1518 & 2.65 & 1000 & 0.43 \\
Coarse aggregate & 1458 & 2.73 & 1000 & 0.47 \\
Pit Gravel & 1329 & 2.63 & 1000 & 0.49 \\
\hline
\end{tabular}

Table 8: Porosity of Aggregate

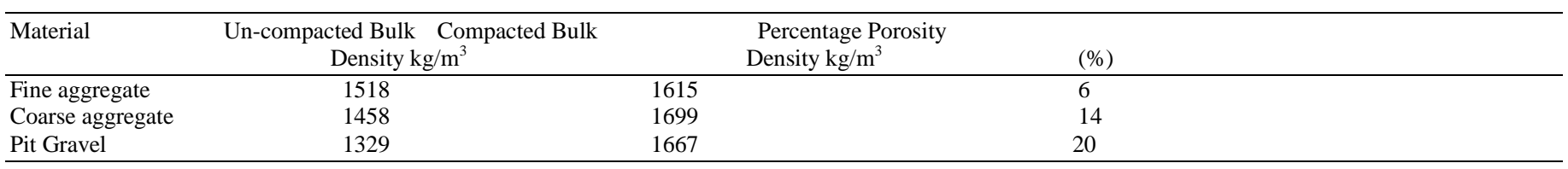


Table 9: Aggregate Impact Value for Coarse Aggregate

\begin{tabular}{llll}
\hline Test No & 1 & 2 & 3 \\
\hline Weight of Mould, $\mathrm{W}_{1}(\mathrm{Kg})$ & 2.71 & 2.71 & 2.71 \\
Weight of Mould + Compacted Sample $\mathrm{W}_{2}(\mathrm{Kg})$ & 3.51 & 3.56 & 3.61 \\
Weigh of Fraction Passing 2.36mm, $\mathrm{W}_{3}(\mathrm{Kg})$ & 0.15 & 0.14 & 0.16 \\
Weight of Sample $\left(\mathrm{W}_{2}-\mathrm{W}_{1}\right)$ & 0.80 & 0.85 & 0.90 \\
Impact Value $=\mathrm{x} 100 \%$ & 18.75 & 16.47 & 17.78 \\
Average Impact Value $(\%)$ & & $17.67 \%$ & \\
\hline
\end{tabular}

Table 10: Aggregate Impact Value for Pit Gravel

\begin{tabular}{llll}
\hline Test No & 1 & 2 & 3 \\
\hline Weight of Mould, $\mathrm{W}_{1}(\mathrm{Kg})$ & 2.71 & 2.71 & 2.71 \\
Weight of Mould + Compacted Sample $\mathrm{W}_{2}(\mathrm{Kg})$ & 3.39 & 3.37 & 3.42 \\
Weigh of Fraction Passing 2.36mm, $\mathrm{W}_{3}(\mathrm{Kg})$ & 0.13 & 0.14 & 0.13 \\
Weight of Sample $\left(\mathrm{W}_{2}-\mathrm{W}_{1}\right)$ & 0.68 & 0.66 & 0.71 \\
Impact Value $=\mathrm{x} 100 \%$ & 19.12 & 21.21 & 18.31 \\
Average Impact Value $(\%)$ & & $19.55 \%$ & \\
\hline
\end{tabular}

Table 11: Aggregate Crushing Value for Coarse Aggregate

\begin{tabular}{llll}
\hline Test No & 1 & 2 & 3 \\
\hline Weight of Mould, $\mathrm{W}_{1}(\mathrm{Kg})$ & 13.25 & 13.25 & 13.25 \\
Weight of Mould + Compacted Sample $\mathrm{W}_{2}(\mathrm{Kg})$ & 17.14 & 17.09 & 17.16 \\
Weigh of Fraction Passing 2.36mm, $\mathrm{W}_{3}(\mathrm{Kg})$ & 1.09 & 1.14 & 1.12 \\
Weight of Compacted Sample only $\left(\mathrm{W}_{2}-\mathrm{W}_{1}\right)$ & 3.89 & 3.84 & 3.91 \\
Crushing Value $=\frac{\mathrm{W} 3}{\mathrm{~W} 2-\mathrm{W} 1} \times 100 \%$ & 28.02 & 29.69 & 28.64 \\
Average Crushing Value $(\%)$ & & $28.78 \%$ & \\
\hline
\end{tabular}

Table 12: Aggregate Crushing Value for Pit Gravel

\begin{tabular}{llll}
\hline Test No & 1 & 2 & 3 \\
\hline Weight of Mould, $\mathrm{W}_{1}(\mathrm{Kg})$ & 13.25 & 13.25 & 13.25 \\
Weight of Mould + Compacted Sample $\mathrm{W}_{2}(\mathrm{Kg})$ & 17.11 & 17.15 & 17.20 \\
Weigh of Fraction Passing 2.36mm, $\mathrm{W}_{3}(\mathrm{Kg})$ & 1.11 & 1.14 & 1.16 \\
Weight of Compacted Sample only $\left(\mathrm{W}_{2}-\mathrm{W}_{1}\right)$ & 3.86 & 3.90 & 3.95 \\
Crushing Value $=\frac{\mathrm{W} 3}{\mathrm{~W} 2-\mathrm{W} 1} x 100 \%$ & 28.76 & 29.23 & 29.37 \\
Average Crushing Value $(\%)$ & & $29.12 \%$ & \\
\hline
\end{tabular}

Table 13: Slump and Compacting Factor Test

\begin{tabular}{llclll}
\hline $\begin{array}{l}\text { Water } \\
\text { Cement(W/C) }\end{array}$ & Mixes & Slump & Compacting & Type of Degree of \\
Factor & & Slump & Workability \\
\hline 0.5 & Control & 58 & 0.93 & True Slump & Medium \\
& Pit Gravel & 52 & 0.90 & True Slump & Medium \\
\hline
\end{tabular}

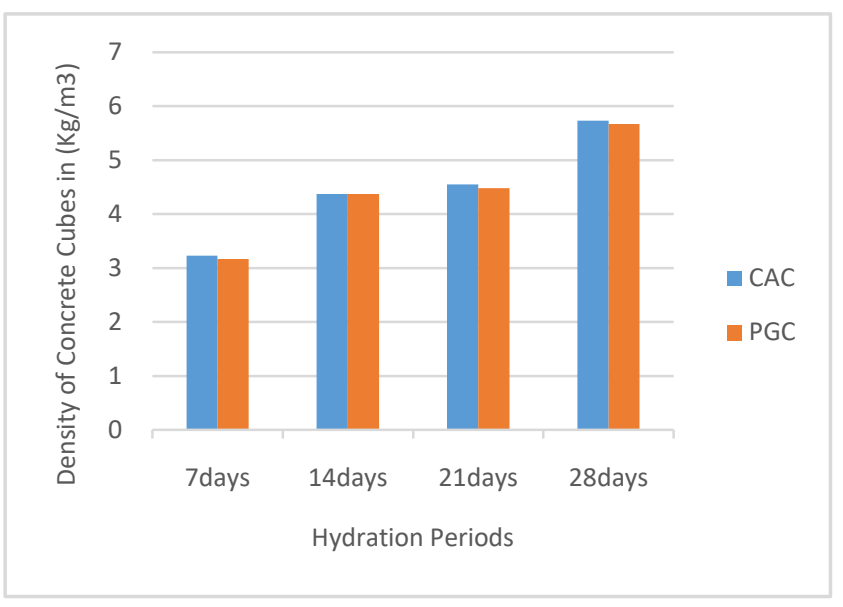

Figure 1: Density of Concrete Cubes

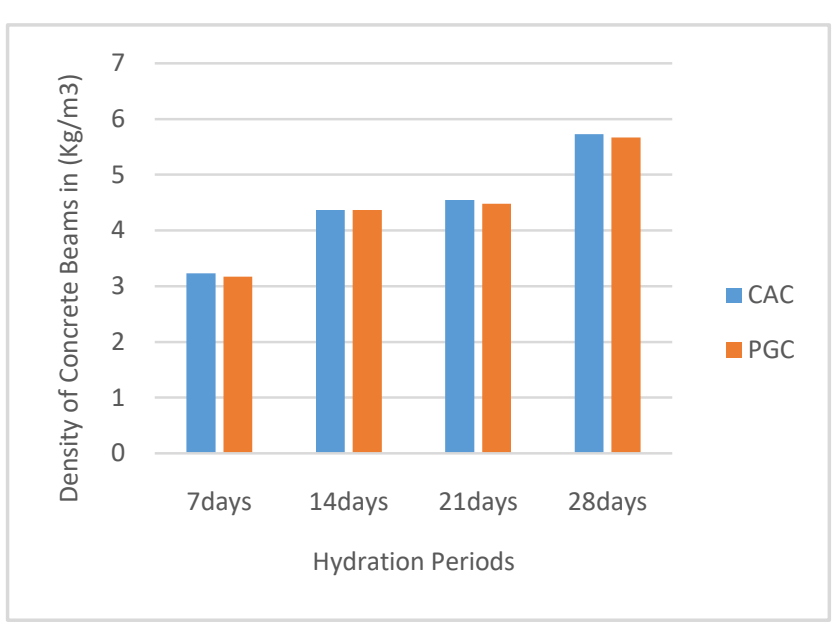

Figure 2: Density of Concrete Beams 


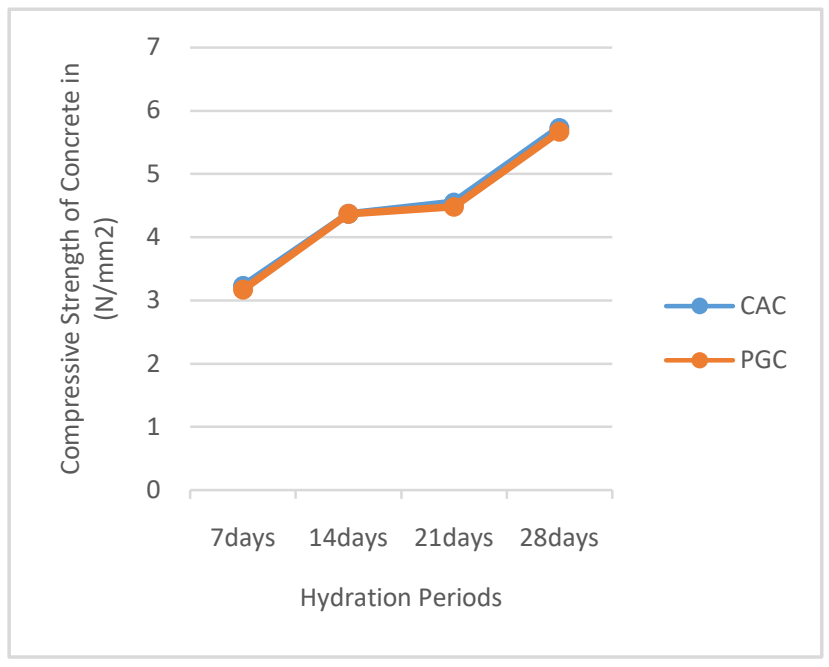

Figure 3: Compressive Strength of Concrete Cubes

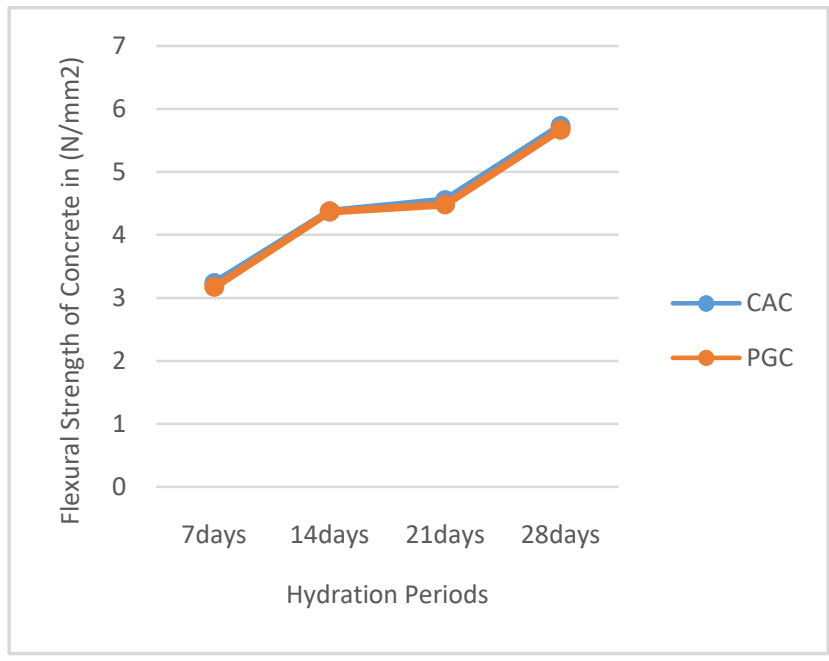

Figure 4: Flexural strength of Concrete Specimen

\section{CONCLUSION}

Pit gravel deposit from Sabon Kaura, Bauchi, Bauchi State Nigeria were found to have good aggregate impact and crushing value as classified by [9]. While normal granite which is a conventional material was classified as a strong material. Pit gravel have high percentage porosity and void ratio when compared with normal granite. The specific gravity, bulk density all fall within specified limit standard. The workability of the fresh mix concrete produced with conventional aggregate and pit gravel all fell within medium classifications. The Compressive strengths of concrete produced with conventional aggregate and pit gravel at 28 days curing meet the requirement for class C25/30 and C20/25 respectively for heavy to normal weight concreting and LC25/28 and LC20/22 respectively for light weight concreting. In addition, at 28 days the flexural strength of concrete produced with conventional aggregate and pit gravel surpassed and or meet up the requirement of $4 \mathrm{~N} / \mathrm{mm}^{2}$. The study suggests that pit gravel can replace conventional aggregate $100 \%$ with a water cement ratio of 0.5 . The density related values of pit gravel in concrete shows similar result with little reduction in density as compared to concrete produced with conventional aggregate at 28 days. The research concluded that pit gravel is a good material for concrete production and can produce a very strong concrete substituting conventional aggregate $100 \%$. Further study recommended on other properties such as shrinkage resistance and durability properties of concrete, also using a different mix ratio and altering water cement ratio is also recommended.

\section{REFERENCES}

[1] Smith, T., and Maillard, P.-L. (2007). The Sustainable Benefits of Concrete Pavement.

[2] Ismail Mohamed A. (2009). Study on the Properties of Palm Oil Fiber. Faculty of Civil Engineering Universti Teknologi Malaysia, 93.

[3] Kulkarni P. P., Chavan P. G., Pagar C. B., (2016). Coconut Shell As Coarse Aggregate In Concrete International conference on recent Trends in Engineering and Science.

[4] Sanjeev K., Ramesh C G., Blessen S. T., Priyansha M,(2016). Aggregate Replacement and Its Usefulness in Cement Concrete for Sustainable Development. A Study on Rubber, Jarosite and Sandstone Aggregates.

[5] Salau M. A., Busari A. O., (2015). Effect of Different Coarse Aggregate Sizes on the Strength Characteristics of Laterized Concrete, 2nd International Conference on Innovative Materials, Structures and Technologies IOP Publishing IOP Conf. Series: Materials Science and Engineering.

[6] Wade, Autade, Belhekar, Jadhav, \& Sathe, (2017). To Study Characteristics of Concrete with Partial Replacement of Coarse Aggregate with Coconut Shell. International Research journal of Engineering and Technology. (IRJET). Pp. 1848- 1851. 4(4) 2017. Retrieved from http://www.irjet.net

[7] British Standard 1377 part 2 (1970). Methods of determination Specific gravity of aggregate. BSI Publication British Standard Institution, London.

[8] Neville, A.M. and Brooks, J.J. (1990). Concrete Technology. English Language Book Society (ELBS)/Longman.

[9] British Standard 812 part 2 (1995). Testing aggregate part 2. Methods of determination of bulk density. BSI Publication British Standard Institution, London.

[10] British Standard, (1983). Testing concrete; Method for determination of slump. BS 1881-102, BSI, Linfordwood, Milton Keynes MK14 6LE, U.K.

[11] BS1881 - 116-117: 1983. Testing Concrete - Method for determination of tensile splitting strength. British Standards Institute, London

[12] Code of practice for design and construction. (2013) Structural use of concrete - Part 1: Hong Kong Special Administrative Region

[13] Abdulazeez, S.A. (2019). Durability properties of composite concrete made with waste glass powder and volcanic ash exposed to aggressive environment. Unpublished M.Tech. Thesis. Abubakar Tafawa Balewa University - Nigeria, 2019.

[14] Neville, A.M. and Brooks, J.J. (1987). Concrete Technology. United Kingdom: Pearson Education Asia Pte. Ltd. 

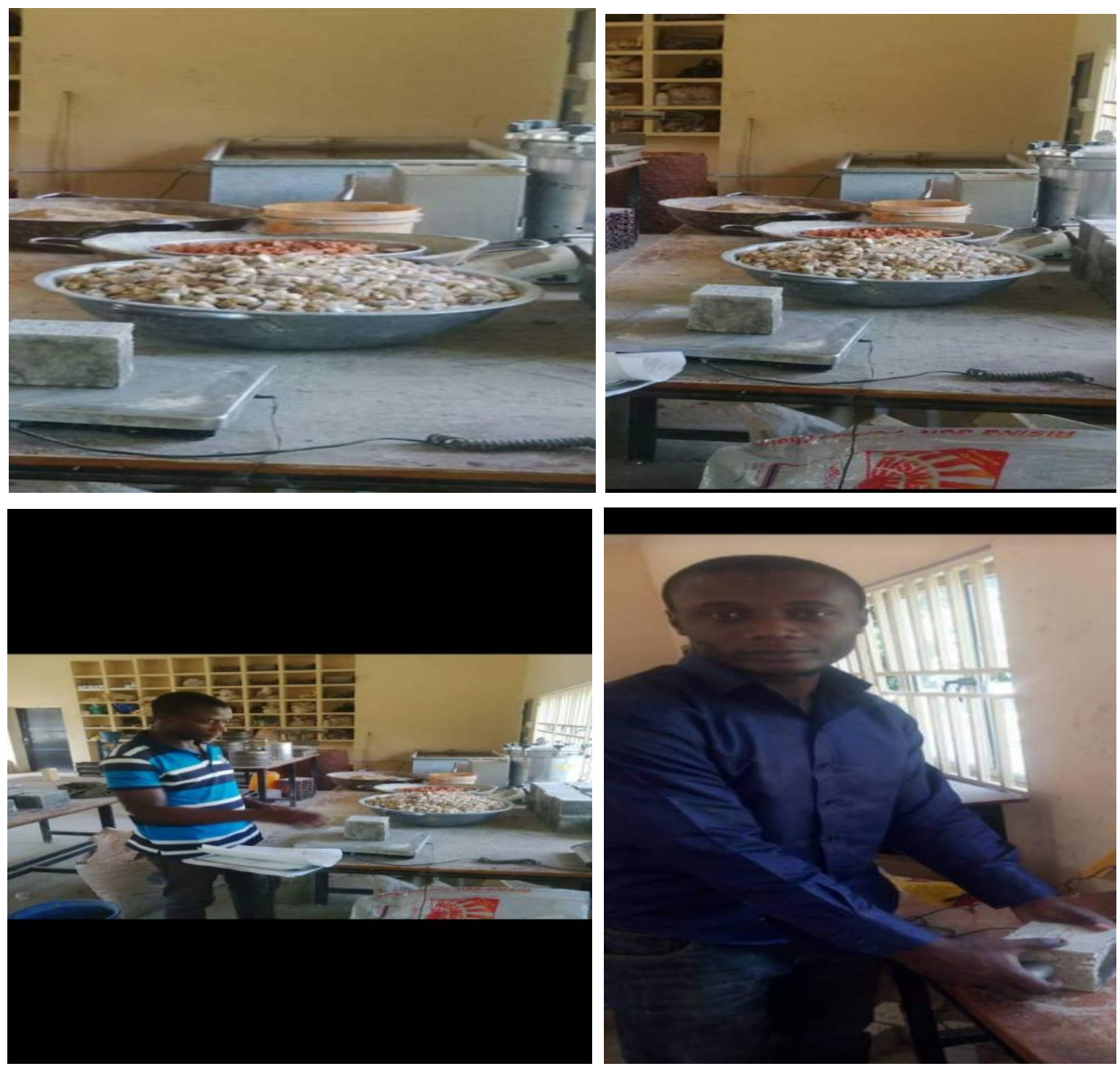